OPEN ACCESS

Edited by:

Dawei Zhang,

Tianjin Institute of Industrial Biotechnology (CAS), China

Reviewed by:

Haiwei Lou,

Henan University of Technology,

China

Zhong-Ji Qian,

Guangdong Ocean University, China

Xudong Feng,

Beijing Institute of Technology, China

*Correspondence: Suying Wang

wsying@tjcu.edu.cn

Haihua Ruan

ruanhaihua@tjcu.edu.cn

Specialty section:

This article was submitted to

Synthetic Biology,

a section of the journal

Frontiers in Bioengineering and

Biotechnology

Received: 25 October 2021 Accepted: 06 December 2021 Published: 17 December 2021

Citation:

Wu X, Wu T, Huang A, Shen Y, Zhang $X$, Song $W$, Wang S and Ruan $H$

(2021) New Insights Into the

Biosynthesis of Typical Bioactive Components in the Traditional Chinese Medicinal Fungus Cordyceps militaris. Front. Bioeng. Biotechnol. 9:801721.

doi: 10.3389/fbioe.2021.801721

\section{New Insights Into the Biosynthesis of Typical Bioactive Components in the Traditional Chinese Medicinal Fungus Cordyceps militaris}

\author{
Xiuyun $W u^{1}$, Tao $W u^{1}$, Ailin Huang ${ }^{1}$, Yuanyuan Shen ${ }^{1}$, Xuanyu Zhang ${ }^{2}$, Wenjun Song ${ }^{1}$, \\ Suying Wang ${ }^{1 *}$ and Haihua Ruan ${ }^{1 *}$
}

${ }^{1}$ Tianjin Key Laboratory of Food Science and Biotechnology, College of Biotechnology and Food Science, Tianjin University of Commerce, Tianiin, China, ${ }^{2}$ New College, University of Toronto, Toronto, ON, Canada

Cordyceps militaris, a traditional medicinal ingredient with a long history of application in China, is regarded as a high-value fungus due to its production of various bioactive ingredients with a wide range of pharmacological effects in clinical treatment. Several typical bioactive ingredients, such as cordycepin, D-mannitol, cordyceps polysaccharides, and $\mathrm{N}^{6}$-(2-hydroxyethyl)-adenosine (HEA), have received increasing attention due to their antitumor, antioxidant, antidiabetic, radioprotective, antiviral and immunomodulatory activities. Here, we systematically sorted out the latest research progress on the chemical characteristics, biosynthetic gene clusters and pathways of these four typical bioactive ingredients. This summary will lay a foundation for obtaining low-cost and high-quality bioactive ingredients in large amounts using microbial cell factories in the future.

Keywords: biosynthesis, cordycepin, d-Mannitol, cordyceps polysaccharides, $\mathbf{N}^{6}$-(2-hydroxyethyl)-adenosine (HEA)

\section{INTRODUCTION}

Cordyceps militaris is an entomopathogenic filamentous fungus, belonging to division Ascomycota, class Sordariomycetes, order Hypocreales, family Clavicipitaceae. C. militaris has been demonstrated to be beneficial in the treatment of male reproductive problems (Chen et al., 2017), chronic kidney (Zhang et al., 2014; Hong et al., 2015), respiratory (Bai et al., 2020), heart, liver (Cheng et al., 2014; Liu et al., 2014; Fan et al., 2018) and lung diseases (Wang et al., 2016), hyperglycemia, hyperlipidemia, and cancer. Wild C. militaris is generally called Yong Chong Cao in China for its parasitizing within the insect host's body in winter and forming grass-like fruiting bodies by absorbing nutrients from host's body in summer. C. militaris, which is considered a model species of the genus, is acknowledged to produce many bioactive secondary metabolites, including cordycepin, D-mannitol, cordyceps polysaccharides, and HEA.

The most direct way to obtain these four bioactive secondary metabolites is to separate and extract them from the wild and artificial cultivated C. militaris in the laboratory (Figure 1) (Tang et al., 2018; Li X. et al., 2019). However, the long growth cycle, harsh environmental requirements and other reasons, resulting in the technical cost of this kind of extraction industry may be relatively high, and it will also increase the burden on the industrial environment.

In recent years, the rise of synthetic biology has enabled many industrial microorganisms to produce various secondary metabolites to satisfy the demand of market (Teh et al., 2019). However, there are no systematical illustration about the synthesis pathways of these biologically active 


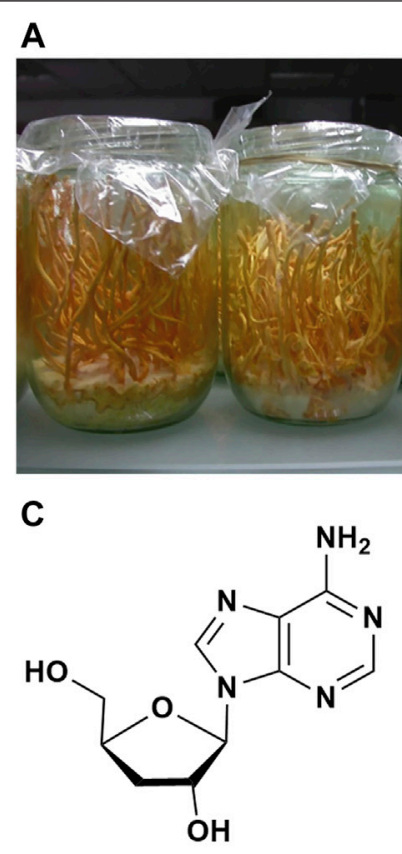

Cordycepin

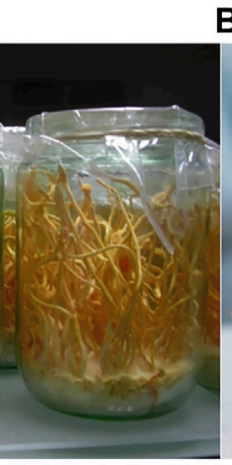

B

D E

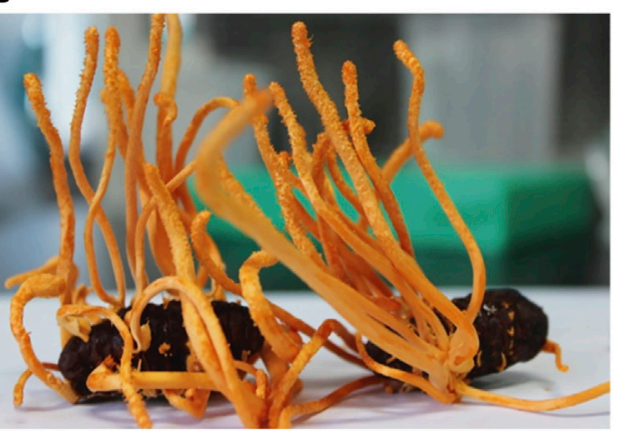

$\overbrace{\sum_{\mathrm{O} H}}^{\mathrm{OH}}$

$\mathrm{OH}$

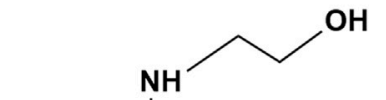




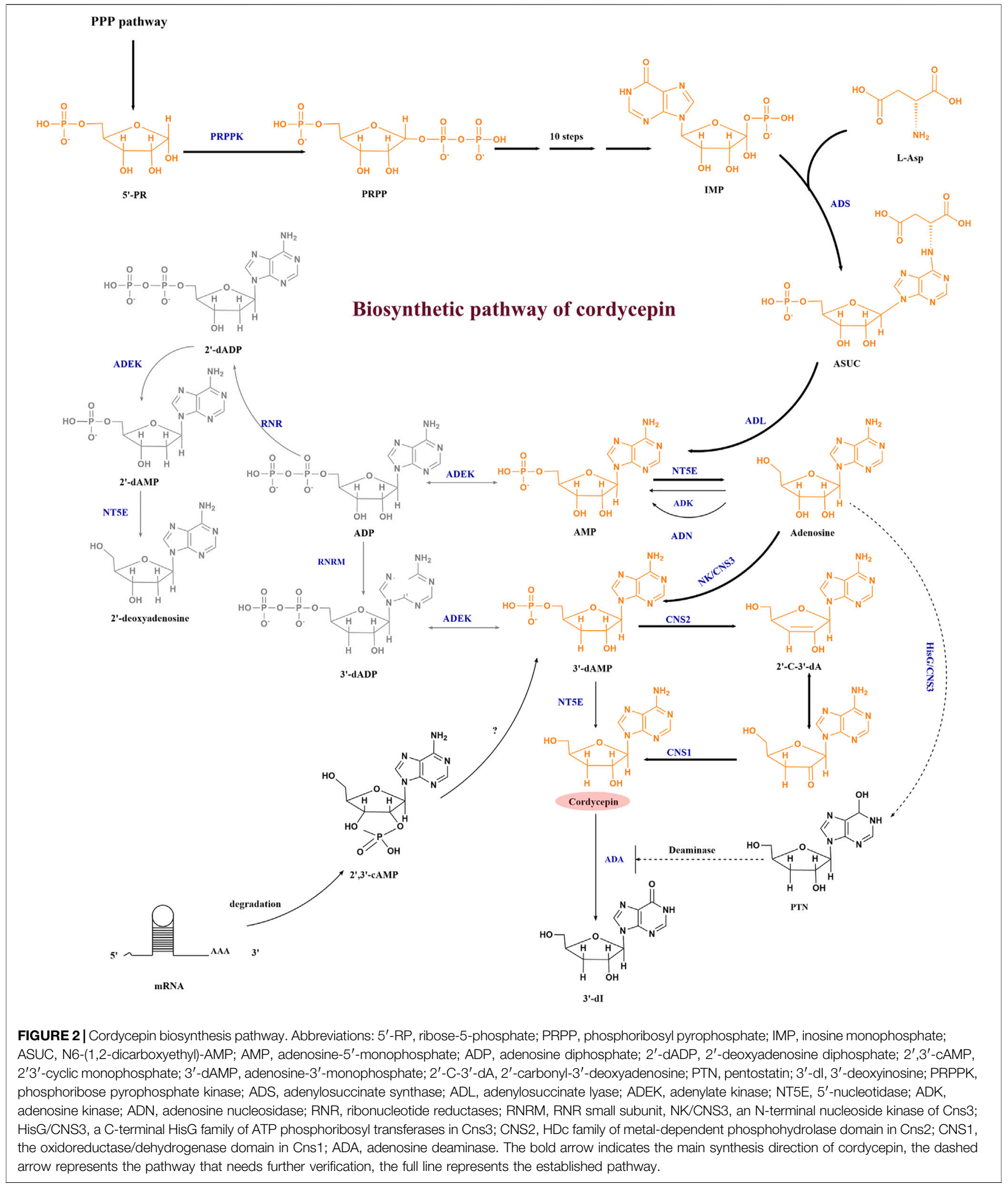

increased by $35 \%$ than parent strain (Kang et al., 2017). Thirdly, a multifunctional plasma mutation system (MPMS) was applied to the improvement of strains, the results showed that the yield of cordycepin obtained from a MPMS treated strain named GYS60 reached to $7.88 \mathrm{mg} / \mathrm{ml}$, which was more than 20 times higher than the yield of the wild-type strain (Zhang et al., 2020a). 
A

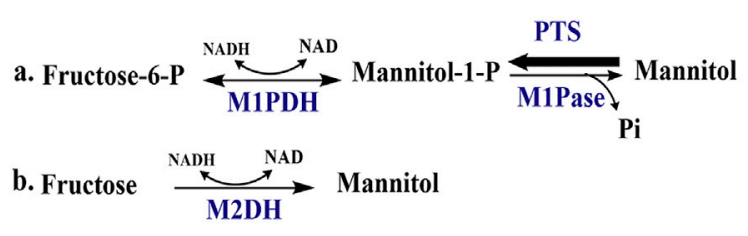

B

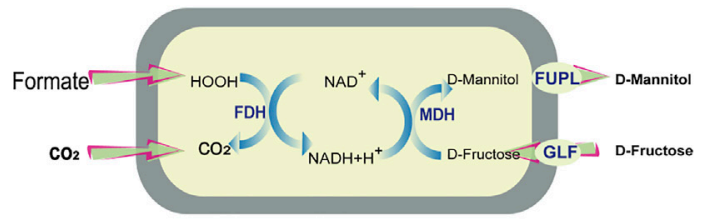

C

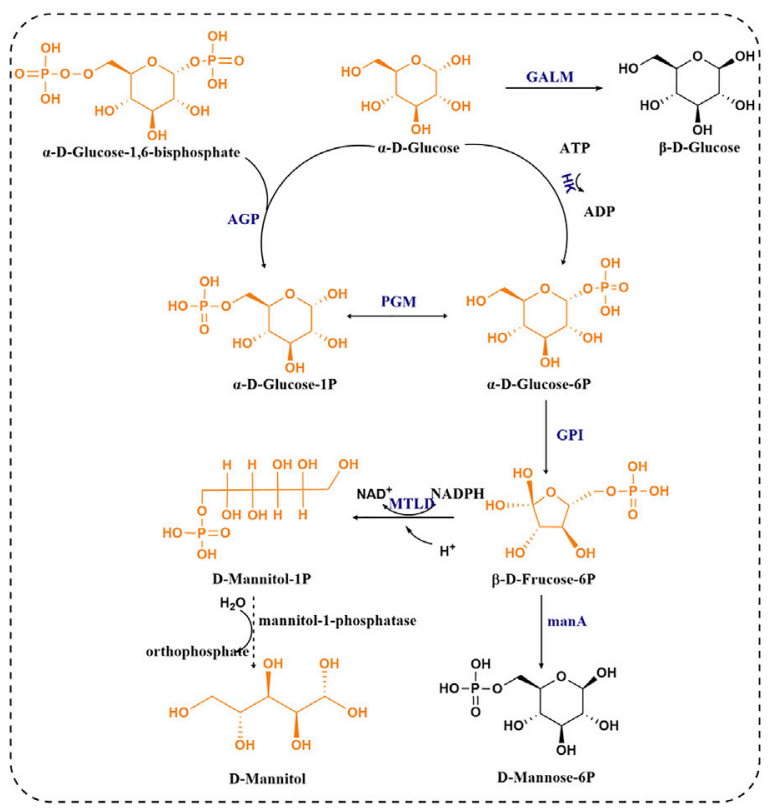

D

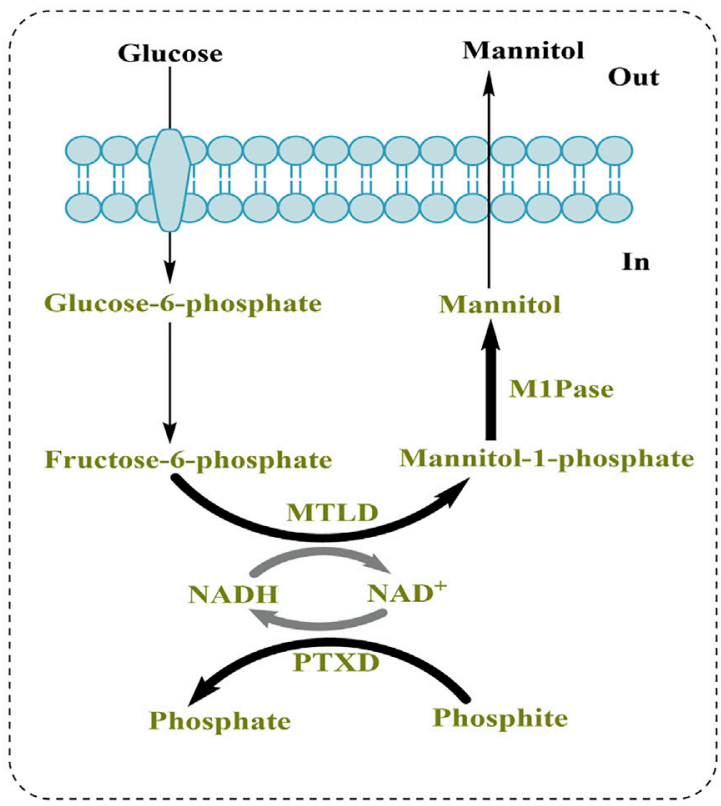

FIGURE 3 | D-mannitol biosynthetic pathway in lactic-acid bacteria, H. sinensis and E. coli. (A) a. Proposed mannitol metabolism in non-lactic-acid bacteria and homofermentative lactic-acid bacteria and b. heterofermentative lactic-acid bacteria PTS: phosphoenolpyruvate-dependent mannitol phosphotransferase system. The size of the arrow indicates the trend of reaction. (B) A recombinant oxidation/reduction cycle in Escherichia coli for D-mannitol formation. (C) The predicted biosynthetic pathway of D-mannitol in H. sinensis. AGP: glucose pyrophosphorylase; GALM: galactose mutarotase; HK: hexokinase; PGM: phosphoglucomutase; GPI: glucose phosphate isomerase; MTLD:mannitol-1-phosphate dehydrogenas; manA: hexokinase-like mRNA coding protein (manA1-manA5). (D) Synthetic pathway constructed in Escherichia coli leading to mannitol production from glucose. Bold arrows indicate overexpression.

At present, increased growth and cordycepin overproduction have been achieved using different $C$. militaris strains, but there are also many problems, such as the long growth cycle of the $C$. militaris and the instability of breeding strain, which hinder its application on an industrial scale. Thus, the construction of cell factories with a short growth cycle capable overproducing cordycepin has become a research hotspot.

\section{Biosynthesis of Cordycepin}

In order to obtain industrial cell factories that overproduce cordycepin, we need to explore the gene cluster needed for cordycepin synthesis and its synthesis pathway in vivo. Although cordycepin was discovered in C. militaris in 1950, the elucidation of its biosynthetic pathway has not been resolved for a long time due to the lack of powerful genome analyzing tools. Untill 2011, the adenosine metabolic pathways in C. militaris and the cordycepin biosynthesis genes were primarily disclosed based on genomics and transcriptomics analysis. The recent development of cordycepin biosynthesis pathways was summarized in Figure 2, which includes three pathways.
The first pathway of cordycepin biosynthesis in C. militaris is shown in yellow. The synthesis starts from PRPP (phosphoribosyl pyrophosphate) pathway, after which inosine monophosphate (IMP) and L-Asp are converted by adenylosuccinate synthase (ADS) to form $\mathrm{N}^{6}$-(1, 2-dicarboxyethyl)-AMP (ASUC). Then, AMP and adenosine are successively formed under the catalysis of adenylosuccinate synthase (ADL) and $5^{\prime}$-nucleotidase (NT5E). With the development of bioinformatics and omics technologies, four highly conserved protein coding genes named cns1-cns4 were found to be related to the metabolism of adenosine in 2017 by comparing large amounts of orthologous proteins between $C$. militaris and A. nidulans with the efforts of Xia's team (Xia et al., 2017). They proved that CNS1-CNS3 were responsible for cordycepin synthesis. The nucleoside/nucleotide kinase domain of CNS3 catalyzed the hydroxyl phosphorylation at the $3^{\prime}-\mathrm{OH}$ position of adenosine to form adenosine- $3^{\prime}$-monophosphate $\left(3^{\prime}\right.$ AMP). At the same time, the C-terminal HisG domain of CNS3 was found to convert adenosine to pentostatin, which can inhibit the deamination reaction of cordycepin. The resulting $3^{\prime}$-AMP is then dephosphorylated to $2^{\prime}$-carbonyl- $3^{\prime}$-deoxyadenosine $\left(2^{\prime}\right.$-C- 


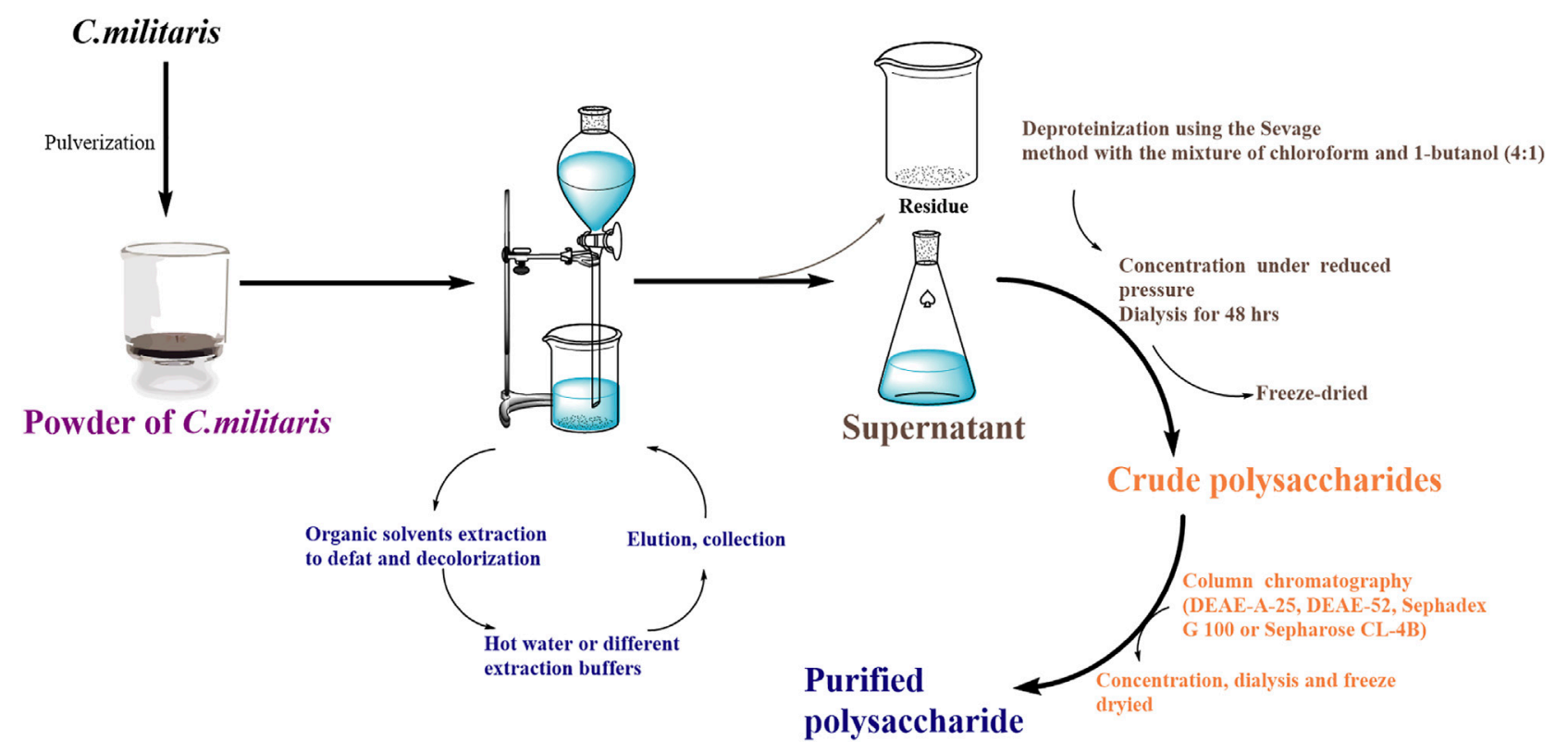

FIGURE 4 | Flow chart of the purification of polysaccharides from C. militaris.

$3^{\prime}-\mathrm{dA}$ ) by CNS2. Cordycepin is finally produced from $2^{\prime}-\mathrm{C}-3^{\prime}-\mathrm{dA}$ by oxidoreductase reactions mediated by CNS1 (Xia et al., 2017). In 2020, Zhao et al. (2019) identified a single gene cluster containing four genes encoding enzymes capable of synthesizing cordycepin and pentostatin simultaneously in $C$. kyushuensis, and named them ck1-ck4. This was consistent with the research of Xia et al. (2017).

The second pathway is shown in grey in Figure 2 in $O$. sinensis, the reduction of adenosine diphosphate (ADP) to $2^{\prime}$ deoxyadenosinediphosphate $\left(3^{\prime}-\mathrm{dADP}\right)$ is catalyzed by highly conserved ribonucleotide reductases (RNR), and then adenylate kinase (ADEK) and $5^{\prime}$-nucleotidase (NT5E) are involved in phosphorylation and dephosphorylation in the adenosine metabolic pathway. RNR, ADEK, and NT5E were also revealed in the $C$. militaris genome in 2011 (Zheng et al., 2011), and both of $C$. militaris and $O$. sinensis have the capability of producing cordycepin. Thus, according to the similarity to $2^{\prime}$ deoxyadenosine biosynthesis, Xiang et al. predicted that the biosynthesis of cordycepin may proceed through a reductive mechanism after transcriptome analysis of the $O$. sinensis fruiting body (Xiang et al., 2014), but they didn't verify the cordycepin biosynthesis pathway. Untill 2017, the recombinant E. coli which expressed CmRNR showed RNR activity on ADP but did not produce 3' -deoxy ADP (Kato et al., 2017), which seemed to deny the participation of RNR in cordycepin biosynthesis in C. militaris. But in 2020, Zhang et al. indicated that the RNR consisted of two subunits: a large one (RNRL) and a small one (RNRM), RNRM could regulate the biosynthesis of cordycepin directly via the reduction of adenosine, as demonstrated by overexpressing RNRM in C. militaris (Zhang et al., 2020b).

The third pathway are branched from the precursor and the direct metabolite of $3^{\prime}$-dAMP. The $3^{\prime}$-AMP of cordycepin precursor can also be synthesized from $2^{\prime}, 3^{\prime}$-cyclic AMP except from $3^{\prime}$-dADP and adenosine, which is degraded from mRNA degradation in C. militaris (Wongsa et al., 2020).

To validate whether some of these gene clusters mentioned above can enable other microbials to produce cordycepin, the cns1-cns3 gene cluster were firstly expressed in $M$. robertsii (Metarhizium robertsii) (a closely related insect pathogenic fungus), and finally the recombinant $M$. robertsii produced cordycepin (Xia et al., 2017). Besides that, the budding yeast, Saccharomyces cerevisiae heterologous expressed either cns1-cns3 or cns1-cns2 could produce cordycepin (Xia et al., 2017; Huo et al., 2021). Therefore, the function of CNS3 in the synthesis of heterologous cordycepin has not yet been confirmed. At present, the specific functions of other related genes in the biosynthetic pathway of cordycepin have yet to be verified, and there are few studies on cordycepin cell factories, and a lot of related explorations are needed.

\section{D-Mannitol}

In 1957, an active substance was first isolated from C. sinensis (Berkeley) Saccardo strain and initially named cordycepic acid (Cao et al.), and in 1963 its structure was revised to D-mannitol (Figure 1D). D-mannitol is a linear six-carbon polyol that can be considered an isomer of D-sorbitol, differing only in the orientation of the $\mathrm{C} 2-\mathrm{OH}$ group. On account of its unique physical and chemical characters, D-mannitol has valuable applications in medicine, fine chemicals, textiles, and food (Duan et al., 2018). It has been shown that D-mannitol can activate mitochondrial ATP-sensitive potassium ( $\left.\mathrm{mK}_{\mathrm{ATP}}\right)$ channels to protect heart (Feige et al., 2021). In addition, $\mathrm{D}$-mannitol can also be a adjunctive therapy for acute promyelocytic leukaemia (Guo et al., 2021). Due to its wide range of applications, D-mannitol had a total market value of USD 209.4 million in 2015, and its demand seems to increase in the future (Wei 
TABLE 1 | Comparison of extraction methods for polysaccharides.

\section{Extraction methods}

Hot or boiling water

Backflow method

Enzyme-assisted

extraction

Ultrasonic extraction

Microwave extraction

Ultra-high pressure

extraction

Subcritical water

extraction

\section{Advantages}

Simple operation, wide range of applications, cheap solvent Controllable temperature, less solvent consumption, simple operation

Specificity, high efficiency and mild reaction conditions

Low extraction temperature, simple operation

High selectivity, simple and fast, can assist other extraction techniques to work together, save solvent, high extraction rate, low cost

Preserve the activity of the extract

Simple equipment, short extraction time, large selection of solvents, less pollution, wide application prospects

\section{Disadvantages}

Short storage time and many product impurities

Low efficiency, long time

Strict reaction conditions, the enzyme is easy to be inactivate, and the conditions need to be optimized

Restricted by ultrasonic attenuation factors, the extraction rate is limited

Less samples processed at one time

High equipment investment

Use more solvents, longer extraction time, and relatively high cost

TABLE 2 | Polysaccharides from C. militaris: extraction methods, characteristics, chemical structures and bioactivities.

\begin{tabular}{|c|c|c|c|c|c|c|}
\hline Living strains & Extraction & Category & Components & Linkages & Bioactivities & References \\
\hline $\begin{array}{l}\text { Cordyceps } \\
\text { militaris NG3 }\end{array}$ & $\begin{array}{l}\text { size exclusion } \\
\text { chromatography (SEC) }\end{array}$ & $\begin{array}{l}\text { Fr-I } \\
\text { Fr-II } \\
\text { Fr-III } \\
\text { Fr-IV }\end{array}$ & - & - & - & Kim, (2003) \\
\hline Cordyceps militaris & $\begin{array}{l}\text { ethanol precipitation, } \\
\text { deproteination and gel- } \\
\text { filtration chromatography }\end{array}$ & $\begin{array}{l}\text { CPS-2 } \\
\text { CPS-3 }\end{array}$ & $\begin{array}{l}\text { Rha:Glc:Gla = 1: } 4.46: 2.43 \\
\text { D-glucose,?-D-glucose }\end{array}$ & $\begin{array}{l}1 \rightarrow 4,1 \rightarrow 6 \text { linkages } \\
1 \rightarrow 4,1 \rightarrow 6 \text { linkages }\end{array}$ & $\begin{array}{l}- \\
-\end{array}$ & $\begin{array}{l}\text { Yu et al. (2004a); } \\
\text { Yu et al. (2004b) }\end{array}$ \\
\hline $\begin{array}{l}\text { Cordyceps militaris } \\
\text { Grown on } \\
\text { Germinatd } \\
\text { Soybeans }\end{array}$ & boiling water & APS & $\begin{array}{l}\text { D-galactose,L- } \\
\text { arabinose,D-xylose, } \\
\text { L-rhamnose, and } \\
\text { D-galacturonic acid }\end{array}$ & $\begin{array}{l}\text { Araf-(1f, f5)-Araf-(1f, } \\
\text { f4)-Galp-(1f and } f 4)- \\
\text { GalAp-(1f residues }\end{array}$ & $\begin{array}{l}\text { modulation of the immune } \\
\text { function of macrophages }\end{array}$ & Ohta et al. (2007) \\
\hline Cordyceps militaris & $\begin{array}{l}\text { hot water extraction and } \\
\text { ethanol precipitation }\end{array}$ & $\begin{array}{l}\text { CMP Fr I } \\
\text { CMP Fr II } \\
\text { CMP Fr III }\end{array}$ & $\begin{array}{l}\text { Glu:Gal:Man = 3.28:1.53:1 } \\
-\end{array}$ & $\begin{array}{l}- \\
1 \rightarrow 2,1 \rightarrow 4,1 \rightarrow 6 \\
\text { linkages } \\
-\end{array}$ & $\begin{array}{l}\text { Upregulate the phenotypic } \\
\text { functions of macrophages } \\
-\end{array}$ & Lee et al. (2010) \\
\hline Cordyceps militaris & $\begin{array}{l}\text { hot water and precipitated } \\
\text { by } 50 \% \text { ethanol }\end{array}$ & W-CBP50-II & $\begin{array}{l}\text { ??-glucose,?-mannose } \\
\text { ?-galactose and ??- } \\
\text { arabinose uronic acid and } \\
\text { protein }\end{array}$ & $\begin{array}{l}\text { ?-type glycosidic } \\
\text { linkages }\end{array}$ & antioxidant activities & Chen et al. (2013) \\
\hline Cordyceps militaris & $\begin{array}{l}\text { Soxhlet extraction using } \\
\text { temperature gradient }\end{array}$ & $\begin{array}{l}\beta-(1 \rightarrow 3)-D- \\
\text { glucan }\end{array}$ & D-glucan & $1 \rightarrow 3$ linkages & anti-inflammatory & $\begin{array}{l}\text { Smiderle et al. } \\
(2014)\end{array}$ \\
\hline Cordyceps militaris & $\begin{array}{l}\text { DEAE-52 cellulose anion } \\
\text { exchange column and a } \\
\text { Sepharose } \\
\text { G-100 column }\end{array}$ & CMN1 & $\begin{array}{l}\text { L-rhamnose, L-arabinose, } \\
\text { D-mannose, D-galactose }\end{array}$ & $\begin{array}{l}1 \rightarrow 2,1 \rightarrow 3,1 \rightarrow 4 \\
1 \rightarrow 6 \text { linkages }\end{array}$ & anti-hypoxic & Dong et al. (2015) \\
\hline Cordyceps militaris & $\begin{array}{l}\text { Subcritical water } \\
\text { extraction (SWE) }\end{array}$ & $\begin{array}{l}\text { CMP-W1 } \\
\text { CMP-S1 }\end{array}$ & $\begin{array}{l}\text { Glu:Gal:Man }=1: 1.29: 2.84 \\
\text { Glu:Gal:Man }=1: 1.09: 2.05\end{array}$ & $\begin{array}{l}- \\
-\end{array}$ & immunostimulatory activity & Luo et al. (2017) \\
\hline Cordyceps militaris & Column chromatography & CM3-SII & Glu:Gal:Man = 1:3.7:10.6 & $\begin{array}{l}1 \rightarrow 2,1 \rightarrow 4,1 \rightarrow 6 \\
\text { linkages }\end{array}$ & Hypolipidemic & $\begin{array}{l}\text { Wang et al. } \\
(2021)\end{array}$ \\
\hline $\begin{array}{l}\text { Cordyceps militaris } \\
\text { cultivated on hull- } \\
\text { less barley }\end{array}$ & $\begin{array}{l}\text { hot water extraction and } \\
\text { ethanol precipitation }\end{array}$ & SDQCP-1 & Glu:Gal:Man = 1:9.7:13.3 & $\begin{array}{l}1 \rightarrow 2,1 \rightarrow 4,1 \rightarrow 6 \\
\text { linkages }\end{array}$ & $\begin{array}{l}\text { antioxidant and } \\
\text { immunomodulatory }\end{array}$ & $\begin{array}{l}\text { Zhang et al. } \\
\text { (2020c) }\end{array}$ \\
\hline
\end{tabular}

et al., 2021). Therefore, many scientists have studied strategies to increase the biotechnological production of D-mannitol.

There are currently three main methods to produce D-mannitol, including chemical synthesis and biosynthesis. The chemical synthesis of D-mannitol starts from D-fructose, D-glucose, and D-mannose. And then after catalytic hydrogenation, the final product is obtained through stepwise crystallization (Jin and $\mathrm{Li}, 2006$ ). However, the process of chemical synthesis requires large amounts of energy and produces problematic by-products, which severely limit its wide application (Cao et al., 2018). Besides that, there have many organisms in nature that can synthesize D-mannitol, such as higher plants, algae, lichens, bacteria and fungi. However, in photosynthetic organisms, D-mannitol is the main primary photosynthetic product and energy storage compound, its level is difficult to reach a large amount without affecting the growth of organisms. Therefore, more promising strategies have been exploited on lactic acid 


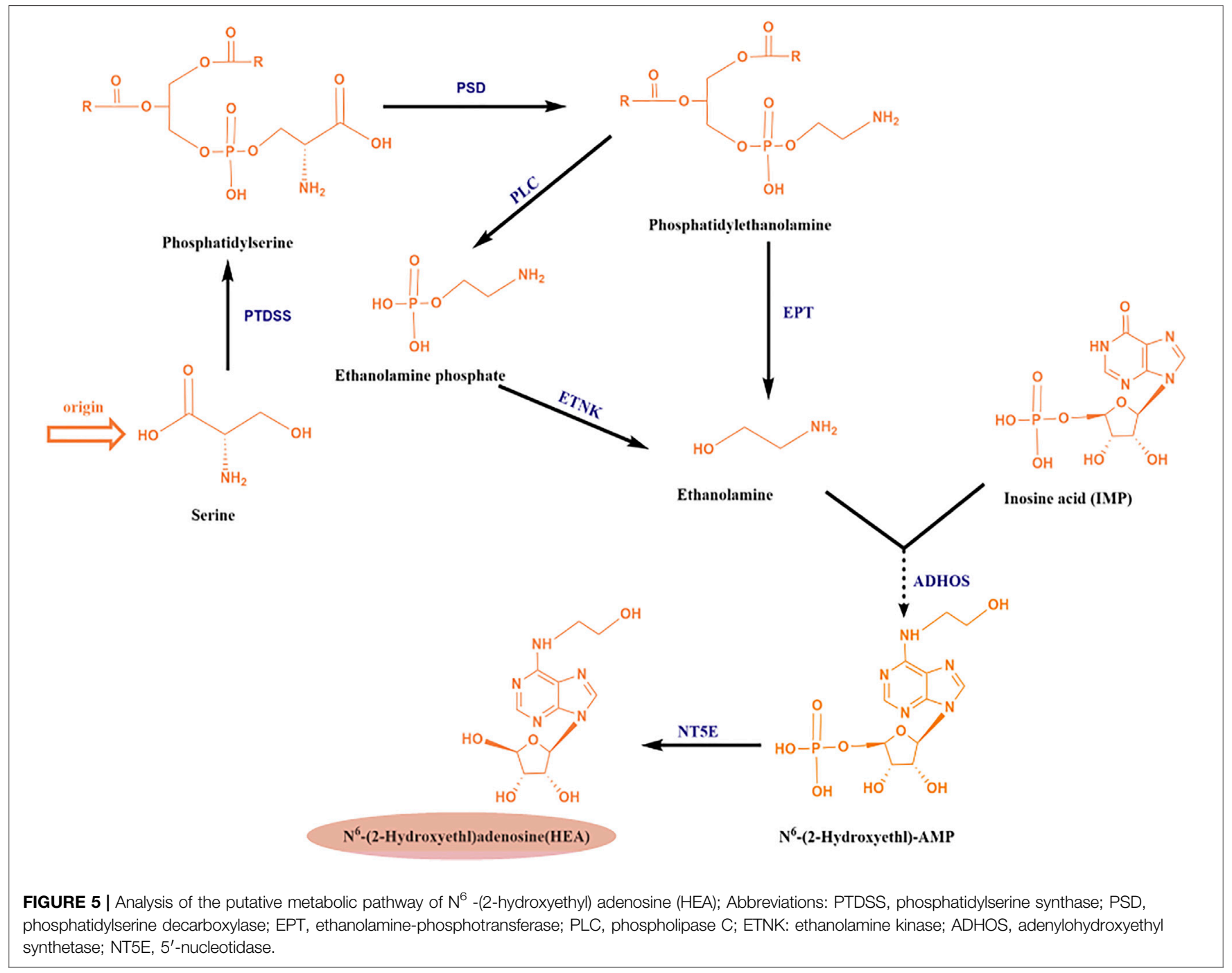

bacteria, filamentous fungi and Escherichia coli to produce D-mannitol via environmentally friendly biosynthetic pathways in recent decades.

\section{Synthesis of D-Mannitol in Lactic Acid Bacteria}

Lactic acid bacteria (LAB) are known to be a type of bacteria that own the capability of efficiently converting sugars into D-mannitol. Based on the latest report, fermentation of apple juice with the well-known D-mannitol-producing LAB strain Leuconostoc citreum TR116, the bioreactor reduction of sugar was scaled up to $98.6 \mathrm{~g} / \mathrm{L}(83 \%)$ and the production of D-mannitol was achieved to $61.6 \mathrm{~g} / \mathrm{L}$ (Rice et al., 2020). The high D-mannitol production of LAB made them into the first organism to be studied for D-mannitol biosynthesis. Thus, the biosynthesis of D-mannitol in LAB is the most clearly studied pathway at present (as shown in Figure 3A). In homofermentative lactic-acid bacteria, the synthetic
D-mannitol is from fructose-6-P, under the catalysis of mannitol-1-phosphate dehydrogenase (M1PDH) and mannitol-1-phosphatase (M1Pase), and fructose-6-P is transformed into mannitol-1-P and then eventually form D-mannitol as shown Figure $\mathbf{3 A}$ a. However, the reaction that $\mathrm{D}$-mannitol as a carbon source and converted into mannitol-1-P by a phosphoenolpyruvate-dependent specific phosphortransferase system (PTS) is the main reaction between mannitol-1-P and D-mannitol, and this pathway is usually used to degrade instead of form D-mannitol. Therefore, in order to establish efficient D-mannitol production, Xiao, H., et al. characterized how the D-mannitol genes (including M1PDH encoding gene $m t l D$, PTS encoding genes $m t l A$ and $m t l F$, and the regulator MtlR encoding gene $m t l R$ ) in L. lactis were organized. Finally, by overexpressing the $m t l D$ gene and using stationary-phase cells as biocatalysts, they attained $10.1 \mathrm{~g} / \mathrm{L}$ D-mannitol with a $55 \%$ yield. To the best of our knowledge, this remains the highest titer ever reported for $L$. lactis (Xiao et al., 2021). By contrast, the D-mannitol from 
TABLE 3 | Comparison of four bioactives existing methods of acquisition.

\begin{tabular}{|c|c|c|c|c|}
\hline Bioactives & $\begin{array}{l}\text { Existing methods of } \\
\text { acquisition }\end{array}$ & Productivity & Advantages & Disadvantages \\
\hline \multirow[t]{3}{*}{ Cordycepin } & $\begin{array}{l}\text { C. militaris } \\
\text { fermentation }\end{array}$ & $\begin{array}{l}\text { 6,200 mg/L (fermentation broth) Sari et al. } \\
(2016) \\
6.63 \text { mg/g (sclerotium) Kang et al. (2017) }\end{array}$ & Relatively high yield & $\begin{array}{l}\text { Strains degeneracy, long } \\
\text { fermentation cycle }\end{array}$ \\
\hline & Chemical synthesis & $\begin{array}{l}36 \% \text { (starting from adenosine) Huang } \\
\text { et al. (2017) }\end{array}$ & $\begin{array}{l}\text { Convenient, quick effect, controllable } \\
\text { conditions }\end{array}$ & $\begin{array}{l}\text { High cost for the treatment of the } \\
\text { pollution }\end{array}$ \\
\hline & Microbial cell factory & $\begin{array}{l}137.27 \mathrm{mg} / \mathrm{L} \text { (Recombinant } \\
\text { Saccharomyces cerevisiae fermentation } \\
\text { broth) Huo et al. (2021) }\end{array}$ & $\begin{array}{l}\text { Low cost and less pollution, short } \\
\text { fermentation cycle, conducive to industrial } \\
\text { production }\end{array}$ & $\begin{array}{l}\text { Lower yield than C. militaris } \\
\text { fermentation system }\end{array}$ \\
\hline \multirow[t]{4}{*}{ D-mannitol } & $\begin{array}{l}\text { Bioreactor } \\
\text { fermentation }\end{array}$ & $\begin{array}{l}61.6 \mathrm{~g} / \mathrm{L} \text { (fermentation broth with fructose } \\
\text { as substrate) Rice et al. (2020) }\end{array}$ & Relatively high yield & $\begin{array}{l}\text { High fermentation cost, difficult to } \\
\text { remove undesirable metabolites }\end{array}$ \\
\hline & $\begin{array}{l}\text { Chemical hydrgenation } \\
\text { of high-fructose }\end{array}$ & $\begin{array}{l}\text { 65\% (starting from D-sorbitol, D-glucose, } \\
\text { D-fructose) Jin and Li (2006) }\end{array}$ & Relatively high yield & $\begin{array}{l}\text { Requires high pressures, high } \\
\text { temperatures, hydrogen gas, } \\
\text { and raney nickel catalyst }\end{array}$ \\
\hline & Biotransformation & $\begin{array}{l}\text { 87\% (starting from glucose) Reshamwala } \\
\text { et al. (2014) }\end{array}$ & $\begin{array}{l}\text { High total sugar utilization, without the use } \\
\text { of complex media components and } \\
\text { elaborate process control mechanisms }\end{array}$ & Unstable over a long term \\
\hline & Microbial cell factory & $\begin{array}{l}218 \text { mg/L (fermentation broth) Madsen } \\
\text { et al. (2018) }\end{array}$ & $\begin{array}{l}\text { Short fermentation cycle, low cost and } \\
\text { less pollution }\end{array}$ & Relatively low yield \\
\hline \multirow[t]{2}{*}{ Polysaccharides } & $\begin{array}{l}\text { Cordyceps } \\
\text { fermentation }\end{array}$ & $\begin{array}{l}\text { Varies due to different extraction and } \\
\text { purification methods }\end{array}$ & - & $\begin{array}{l}\text { Lack of standard method of } \\
\text { polysaccharide collection }\end{array}$ \\
\hline & & $\begin{array}{l}\text { Yield can be increased by homologous } \\
\text { co-overexpression of genes involved in } \\
\text { precursor nucleotide sugars biosynthesis } \\
\text { Zhou et al. (2018) }\end{array}$ & $\begin{array}{l}\text { Conducive to genetic manipulation and } \\
\text { metabolic engineering to super-produce } \\
\text { polysaccharides in other fungi }\end{array}$ & Need further research \\
\hline \multirow[t]{2}{*}{$\begin{array}{l}\mathrm{N}^{6} \text {-(2-hydroxyethyl) } \\
\text {-adenosine }\end{array}$} & $\begin{array}{l}\text { Cordyceps } \\
\text { fermentation }\end{array}$ & $\begin{array}{l}94 \text { mg/L (fermentation broth) Chunyu } \\
\text { et al. (2019) }\end{array}$ & Relatively high yield & $\begin{array}{l}\text { Strains degeneracy, long } \\
\text { fermentation cycle }\end{array}$ \\
\hline & Chemical synthesis & $\begin{array}{l}\text { 74\% (acrylic acid and chloroethanol) Dong } \\
\text { and Gao (1996) }\end{array}$ & High yield & High material cost and polluted \\
\hline
\end{tabular}

heterofermentative lactic-acid bacteria is the result of uptaking and utilizing fructose and D-mannitol is synthesized directly from fructose by mannitol-2-dehydrogenase $(\mathrm{M} 2 \mathrm{DH})$ without the synthesis of mannitol-1-P (Figure 3A,B) (Wei et al., 2021).

\section{Synthesis of D-Mannitol in Filamentous Fungi}

Among filamentous fungi, $H$. sinensis is known to produce D-mannitol. In 2016, hexokinase and glucose phosphate isomerase were found to be involved in biosynthetic pathway of D-mannitol, due to their significant upregulation by 5.27 -, and 3.94-fold according to real-time PCR. Moreover, judging from the glycolytic pathway and fructose-mannose pathway, Shan Lin et al. proposed a possible biosynthetic pathway of D-mannitol (shown in Figure 3C).

In this pathway, $a$-D-glucose-1, 6-bisphosphate and $a-D$ glucose are converted by glucose pyrophosphorylase (AGP) into $a-D$-glucose- $1 \mathrm{P}$, which can be interconverted with $\alpha-\mathrm{D}$ glucose-6P by phosphoglucomutase (PGM). $a$-D-glucose is converted into $a$-D-glucose- $6 \mathrm{P}$ under the catalysis of hexokinase $(\mathrm{HK})$, and glucose phosphate isomerase (GPI) converts $\alpha$-D-glucose-6P into $\beta$-D-fruccose-6P and the mannitol-1-phosphate dehydrogenase (MTLD) converts $\beta$-Dfruccose-6P into D-mannitol-1P (Lin et al., 2016b). However, the phosphatase that converts D-mannitol-1P into D-mannitol was not proposed, which might indicate that this enzyme in $H$. sinensis be un-annotated in the protein databases. There are two conceivable reasons to explain this finding. One is that the homology of mannitol-1-phosphatase in $H$. sinensis compared with the known mannitol-1-phosphatases from other species is low, and the other one is that certain unknown phosphatases may replace D-mannitol-1P for generating D-mannitol in $H$. sinensis. Additionally, there might be two branching reactions in this pathway that are not conducive to the synthesis of D-mannitol shown in Figure 3C. Firstly, the $\alpha$-D-glucose at the beginning of the reaction can be converted into $\beta$-D-glucose under the catalysis of galactose mutarotase (GALM). Secondly, before D-mannitol$1 \mathrm{P}$ is produced, a part of the substrate $\beta$-D-fruccose-6P can be converted into $\mathrm{D}$-mannose-6P under the action of a hexokinaselike mRNA coding protein (manA).

\section{Synthesis of D-Mannitol in Recombinant Escherichia Coli}

D-mannitol can also be produced by constructing engineered Escherichia coli, which can be divided into the following three stages according to different substrate sources. Firstly, in 2004, a recombinant $E$. coli strain was constructed as biocatalyst for the whole-cell biotransformation of D-fructose into D-mannitol, and the introduction of a gene encoding a D-fructose transporter protein (GLF) from Zymomonas mobilis enabled the cells to import D-fructose (Figure 3B). Finally, the recombinant E. coli BL21 (DE3) expressing $g l f, f d h$ and $m d h$ was able to 
form $362 \mathrm{mM}$ D-mannitol from an initial $500 \mathrm{mM}$ D-fructose of within $8 \mathrm{~h}$, and the molar yield $Y_{\mathrm{D} \text {-mannitol/D-fructose }}$ reached $84 \%$ and a specific productivity was more than $4 \mathrm{~g}$ D-mannitol $\mathrm{g}^{-1}$ (cell dry weight) $\mathrm{h}^{-1}$ (Kaup et al., 2004). In order to overcome the instability of the recombinant strain, which possibly caused by factors such as the internal $\mathrm{pH}$ change of the cells, loss of cofactor $\mathrm{NAD}$, high formate concentrations and export of D-mannitol, the fupL gene was additionally expressed in biotransformation experiments, and the final D-mannitol productivity of the strain was enhanced by $20 \%$ (Heuser et al., 2009).

Secondly, in order to convert D-glucose to D-mannitol, an intracellular glucose isomerase, formate dehydrogenase, D-mannitol dehydrogenase, glucose isomerase, and glucose facilitator were co-expressed in the E. coli strain I, resulting in the production of up to $821 \mathrm{mM} \mathrm{D}$-mannitol at the optimized $\mathrm{pH}$ and temperature (Kaup et al., 2005). To construct a recombinant E. coli strain which can convert glucose into D-mannitol efficiently without the assistance of extracellular enzymes, Reshamwala et al. (2014) assembled a synthetic pathway (shown in Figure 3D) in E. coli to change carbon flow towards D-mannitol production by expressing two native enzymes from the protozoan parasite Eimeria tenella. Mannitol-1-phosphate dehydrogenase (MTLD) reduced fructose-6-phosphate to mannitol-1-phosphate, and mannitol1-phosphatase (M1Pase) dephosphorylated mannitol-1phosphate to yield D-mannitol. The reduction of fructose-6phosphate is accompanied with the oxidation of $\mathrm{NADH}$, and for the sake of regenerating $\mathrm{NADH}$, the phosphite dehydrogenase (PTXD) of Pseudomonas stutzeri was expressed to make it the ability to catalyze the almost nonreversible oxidation of phosphite into phosphate, and at the same time $\mathrm{NAD}^{+}$was reduced into NADH. D-mannitol was then transported across the membrane and released into the culture supernatant, whereby a molar yield of $87 \%$ was achieved without using complex media components and elaborate process control mechanisms (Reshamwala et al., 2014).

In recent years, new insights have emerged on the D-mannitol biosynthetic pathway, especially after the first algal genes involved in D-mannitol production were identified in the model brown alga Ectocarpus (Rathor et al., 2020). However, to accomplish simplifying the engineering process and generate ready-made protein modules, their functionality in heterologous systems remains to be tested. Madsen et al. (2018) expressed a mannitol-1-phosphate dehydrogenase (M1PDH) and a mannitol-1-phosphatase (M1Pase) by fusing an enzyme from the marine alga Micromonas pusilla in E. coli and successfully constructed simpler way to assemble and optimize recombinant metabolic pathways to produce the building blocks of D-mannitol.

To sum up, these three synthesis methods are currently different in the degree of industrial application. For LAB, it is an important group of microorganisms for fermentation of a large range of products, such as yogurt, soy sauce, antiseptic substance and so on. Its fermentation technology is relatively mature and controllable, so it is usually used in industry to produce $\mathrm{D}$-mannitol by fermentation with fructose as a substrate. However, lactic acid bacteria fermentation requires a large amount of fructose, which is costly, and undesirable metabolites are difficult to remove. For filamentous fungi, D-mannitol is one of important active ingredients formed by direct reduction of fructose-6phosphate, but the pathway between D-mannitol-1P and D-mannitol needs to be further verified. Once this approach is verified, we can try to apply it to the construction of mannitol cell factories. For recombinant E. coli, i) by introducing exogenous genes, substrates and product transporters, $E$. coli can be used as a biocatalyst to produce D-mannitol with fructose or glucose. ii) by transferring exogenous fusion proteins into $E$. coli to produce D-mannitol.

\section{CORDYCEPS POLYSACCHARIDES}

C. militaris polysaccharides represent a class of biological macromolecules with diverse structures and extensive physicochemical properties. Many studies have shown that polysaccharides isolated from artificial cultured C. militaris have diverse pharmacological activities, including antitumor (Ukai et al., 1983; Kim et al., 2001), anti-inflammatory and immunoregulatory activities (Yu et al., 2004a). On account of the diversities in raw materials, extraction and purification methods, different cordyceps polysaccharides with diverse structures and bioactivities have been extracted and identified from C. militaris. To the aspect of its clinical application, the main hindrance was the repeatability, reliability and consistency of cordyceps polysaccharides preparation (Zhang et al., 2019). Recently, scientists mainly put the focus on establishing a standard method for the extraction and preparation of cordyceps polysaccharides, the pharmaceutical activity of the obtained cordyceps polysaccharides and the study of the cordyceps polysaccharides biosynthesis pathway.

\section{Extraction, Purification and Identification of Cordyceps Polysaccharides}

To our knowledge, many methods were used to extract polysaccharides from C. militaris, such as pure water, acidic/ alkaline solutions, or heated buffer solutions as shown in Figure 4. Although hot or boiling water is the most convenient solvent for the extraction of cordyceps polysaccharides, the extraction time is too long and the extraction rate is too low, so some new extraction methods have recently been exploited to improve the extraction efficiency, such as microwave extraction, ultra-high pressure extraction, subcritical water extraction, ultrasonic extraction, and enzyme-assisted extraction (Zhang et al., 2019; Park and Lee, 2021), and the differences between these extraction methods are shown in Table $\mathbf{1}$.

Due to the complex chemical structure of fungal polysaccharides, its extraction from the same raw material can also have different structures and exhibit different biological activities. In order to study the structures of 
these cordyceps polysaccharides in detail, many studies were done on the structure and function of cordyceps polysaccharides. At the beginning, most of the reports mainly focused on the extraction of cordyceps polysaccharides but didn't further disclose the components, linkages and bioactivities of the extracted cordyceps polysaccharides due to the lack of valid methods. For example, as shown in Table 2, Kim S W et al. firstly obtained four groups of polysaccharides (named as Fr-I, Fr-II, Fr-III, and Fr-IV) from the culture filtrates of C. militaris, however, those components, linkages and bioactivities were not analyzed in detail (Kim, 2003).

In 2004, ethanol precipitation, deproteination and gelfiltration chromatography were sequently applied to purify polysaccharides from the hot-water extracted C. militaris, and obtained four fractions as shown in Table 2. Their formula weights were detected using gel-filtration chromatography, and the structures of CPS- 2 and CPS-3 were linked by $1 \rightarrow 4$ or $1 \rightarrow 6$ linkage, which were elucidated by sugar analysis, Smith degradation, IR and 13C-NMR spectroscopy (Yu et al., 2004b). In 2010, Lee J S et al. used DEAE-cellulose and Sepharose CL-6B column chromatography to obtain the crude water-soluble polysaccharide CMP (C. militaris polysaccharide) from the fruiting bodies of $C$. militaris after hot water extraction and ethanol precipitation, termed CMP Fr I, CMP Fr II, and CMP Fr III (Lee et al., 2010). Adequate evidences showed that these $C$. militaris polysaccharides own the activities of antioxidant (Chen et al., 2013), antiangiogenetic (Zeng et al., 2014), antiinflammatory (Smiderle et al., 2014), anti-hypoxic (Dong et al., 2015), and immunostimulatory activities (Luo et al., 2017).

\section{The Biosynthesis of Cordyceps Polysaccharides}

Researches on polysaccharides biosynthesis of other organisms, including overexpression of key polysaccharide biosynthetic genes (Zhou et al., 2018), joint expression of multiple genes (Qu et al., 2022), blocking polysaccharide synthesis bypass (Lei et al., 2020), etc. are all feasible ways to increase yield. However, because of the structural determination of cordyceps polysaccharides is still limited, the disclosure of synthesis pathway is not clear until now, the research level of polysaccharide biosynthesis is lower than that of other active substances in Cordyceps. This complicated situation has also led to the current lack of researches on the biosynthesis of cordyceps polysaccharides.

In 2016, a study by Shan Lin et al. (Lin et al., 2016a) opened a significant avenue for finding key enzymes involved in the cordyceps polysaccharide biosynthesis pathways. To enhance the cordyceps polysaccharide (CP) production from submerged cultivation of $H$. sinensis, $2 \mathrm{mM}$ of manganese sulfate on day 0 was the optimal amount and timing of addition, and the $\mathrm{CP}$ production reached to the optimum with $5.33 \%$, which was increased by $93.3 \%$ compared with the control. Notably, they found that the intracellular mannose content decreased by $43.1 \%$ during cultivation under manganese stimulation, and the consumption of mannose just corresponded with the accumulation of CP. This mannose biosynthesis pathway was the first verified pathway which constituted a vital section of $\mathrm{CP}$ biosynthesis, and the transcriptional levels of the biosynthetic genes indicated that the transcription of cordyceps polysaccharides synthesis related genes (cpsA) upregulated 5.35-fold significantly, implicating a crucial gene involved in both mannose and CP biosynthesis. However, the exact relationship between mannose and $\mathrm{CP}$ biosynthesis is still unknown.

\section{$\mathbf{N}^{6}$-(2-Hydroxyethyl)-Adenosine}

$\mathrm{N}^{6}$-(2-hydroxyethyl)-adenosine (HEA) is a derivative of adenosine that was the first identified calcium ion channel antagonist from biological sources. As early as 1983, Furuya et al. isolated HEA from the hyphae of Cordyceps grown in liquid culture, and this pioneering finding was published in phytochemistry.

The molecular weight of HEA is 311.29 , its molecular formula is $\mathrm{C}_{12} \mathrm{H}_{17} \mathrm{~N}_{5} \mathrm{O}_{5}$, and its structural formula is shown in Figure 1E. It possesses many activities, such as protection against ultraviolet radiation, blood-thinning, anti-inflammatory (Li I.-C. et al., 2019; Wang X. et al., 2019; Chyau et al., 2021), analgesic, and antihypertensive activities (Li I.-C. et al., 2019), protective effects against diabetic kidney disease (Wang X. et al., 2019), as well as inhibiting the proliferation of tumor cells, protecting the brain (Zhang et al., 2016), and inducing apoptosis of gastric carcinoma cells (Xie et al., 2020). HEA is generally regarded as being at the intersection of medical care, cosmetics and biological defense. Consequently, it is considered the most important biologically active ingredient to measure the quality of Cordyceps products. Compared with other compounds obtained from Cordyceps, such as the well-known cordycepin, there are few patents related to HEA. The research on HEA is still in the early stage of exploration. At present, there are fewer studies on the screening and hybridization of HEA-producing strains, and more studies focused on the physiological effects of HEA.

Recently, an enzyme from C. militaris with $74 \%$ amino acid sequence similarity to adenylosuccinate synthetase (a key enzyme for adenosine synthesis) was identified by bioinformatic analyses, which suggested that the biosynthesis of HEA was probably similar to that of the conversion of inosine monophosphate (IMP) to adenosine (shown in Figure 2 in grey above). Accordingly, a hypothetic biosynthesis pathway for $\mathrm{N}^{6}$-(2-hydroxyethyl) adenosine in $C$. militaris was proposed as shown in Figure 5 (Chen et al., 2021). Similar to the conversion of IMP and L-aspartate into $\mathrm{N}^{6}-(1,2-$ dicarboxyethyl)-AMP by adenylosuccinate synthetase, IMP and ethanolamine can be converted into $\mathrm{N}^{6}$-(2-hydroxyethyl)-AMP by adenylyl hydroxyethyl synthetase, and $\mathrm{N}^{6}$-(2-hydroxyethyl)AMP is subsequently dephosphorylated to yield HEA.

At present, there are no other report on the biosynthetic pathway of HEA, and in-depth study of its biosynthetic mechanism will open up new ways for the wide application of HEA. Therefore, elucidating the synthesis pathway of HEA at the protein level, identifying the HEA biosynthesis gene clusters, cloning the enzyme-coding genes related to HEA synthesis, and increasing the output of HEA through metabolic engineering, will be a breakthrough in the research of HEA. 


\section{CONCLUDING REMARKS AND FUTURE PERSPECTIVES}

C. militaris is closely related to the highly prized $O$. sinensis, both of them have been reported without toxicity based on the results of chromosomal aberration of CHL cells, Ames test, acute toxicity test and $\mathrm{MN}$ test of bone marrow cells. In addition, compared with $O$. sinensis, C. militaris has lower cost of cultivation (Gong et al., 2003; Gong et al., 2004; Long et al., 2021), which makes it a promising substitute for $O$. sinensis. In nature, the formation of $C$. militaris fruiting bodies requires a specific ecological environment and host insects, which leads to its scarcity as a natural resource. In view of the severe situation of the limited natural resources of $C$. militaris and the long artificial cultivation cycle, researches have attempted to increase the output of various bioactive components using strategies including chemical synthesis, microbial fermentation, and biosynthesis. And we compared these existing methods of obtaining the four active substances mentioned above in Cordyceps in Table 3. Among them, biosynthesis is undoubtedly the most popular and promising approach due to its low impact on the health and the environment.

In future research, synthetic biology techniques can be used to verify the inferred cordycepin biosynthetic pathway. Metabolic engineering transformation, process engineering optimization and other strategies can be applied to optimize cell factories. For D-mannitol, optimize the cell factory in E. coli probably become the major trend of industrial application. Since the yield of D-mannitol obtained through these referred methods is relatively low, the specific control strategies need to be further studied. For instance, deleting pathways for carbon dissimilation that compete with D-mannitol biosynthesis, using optimized high cell density biotransformation and engineered strains to increase yield. Besides, we can also try to construct D-mannitol-producing strains with other strains with clear genetic background and simple operation. For cordyceps polysaccharides (CP), they have a variety of complex structures and compositions, and genes related to the production of $\mathrm{CP}$ are a large and diverse group, therefore, more in-depth researches are needed to explore

\section{REFERENCES}

Bai, X., Tan, T.-Y., Li, Y.-X., Li, Y., Chen, Y.-F., Ma, R., et al. (2020). The Protective Effect of Cordyceps Sinensis Extract on Cerebral Ischemic Injury via Modulating the Mitochondrial Respiratory Chain and Inhibiting the Mitochondrial Apoptotic Pathway. Biomed. Pharmacother. 124, 109834. doi:10.1016/j.biopha.2020.109834

Cao, H., Yue, M., Liu, G., Du, Y., and Yin, H. (2018). Microbial Production of Mannitol by Lactobacillus Brevis 3-A5 from Concentrated Extract of Jerusalem Artichoke Tubers. Biotechnol. Appl. Biochem. 65 (3), 484-489. doi:10.1002/bab.1590

Chen, X., Wu, G., and Huang, Z. (2013). Structural Analysis and Antioxidant Activities of Polysaccharides from Cultured Cordyceps Militaris. Int. J. Biol. Macromolecules 58, 18-22. doi:10.1016/j.ijbiomac.2013.03.041

Chen, Y.-C., Chen, Y.-H., Pan, B.-S., Chang, M.-M., and Huang, B.-M. (2017). Functional Study of Cordyceps Sinensis and Cordycepin in Male Reproduction: A Review. J. Food Drug Anal. 25 (1), 197-205. doi:10.1016/j.jfda.2016.10.020

Chen, Y., Wu, Y., Li, S., Du, S., Hao, X., Zhang, J., et al. (2021). Large-scale Isolation and Antitumor Mechanism Evaluation of Compounds from the Traditional Chinese Medicine Cordyceps Militaris. Eur. J. Med. Chem. 212, 113142. doi:10.1016/j.ejmech.2020.113142
CP synthesis and its regulatory mechanism. For HEA, its biosynthetic pathway has not been clearly reported so far, the speculated pathway mentioned in our review can be used as an entrance for studying HEA synthesis. In conclusion, this review provides evidence to further improve and study the biosynthesis of the bioactive components of Cordyceps, including cordycepin, D-mannitol, cordyceps polysaccharides and HEA.

\section{AUTHOR CONTRIBUTIONS}

XW and TW: investigated literature, wrote article, drew pictures. $\mathrm{AH}$ and YS: investigated literature. XZ: revised the grammar of the article. WS and SW: supervised the progress of the article. HR: revised the article and pictures, supervised the progress of the article.

\section{FUNDING}

This work was supported by the Youth Program of National Natural Science Foundation of China (Grant no. 21908168), the General Program of National Natural Science Foundation of China (Grant no. 31870122), and the Natural Science Foundation of Tianjin (Grant no. 18JCYBJC96000), Innovation Team Project for Colleges and Universities in Tianjin City (Grant no. TD13-5087), Tianjin“131” innovative talent team (Team no. 201927).

\section{ACKNOWLEDGMENTS}

We thank the current and former members of our laboratories and collaborators for their contributions to this review article. The research field in biosynthesis of kinds of bioactive components is rapidly growing, and we apologize for not being able to cite all the recent publications, due to space limitation.

Cheng, Y. J., Cheng, S. M., Teng, Y. H., Shyu, W. C., Chen, H. L., and Lee, S. D. (2014). Cordyceps Sinensis Prevents Apoptosis in Mouse Liver with D-Galactosamine/lipopolysaccharide-Induced Fulminant Hepatic Failure. Am. J. Chin. Med. 42 (2), 427-441. doi:10.1142/S0192415X14500281

Chunyu, Y.-J., Lu, Z.-M., Luo, Z.-S., Li, S.-S., Li, H., Geng, Y., et al. (2019). Promotion of Metabolite Synthesis in Isaria Cicadae, a Dominant Species in the Cicada Flower Microbiota, by Cicada Pupae. J. Agric. Food Chem. 67 (31), 8476-8484. doi:10.1021/acs.jafc.9b02705

Chyau, C. C., Wu, H. L., Peng, C. C., Huang, S. H., Chen, C. C., Chen, C. H., et al. (2021). Potential Protection Effect of ER Homeostasis of N(6)-(2Hydroxyethyl)adenosine Isolated from Cordyceps Cicadae in Nonsteroidal Anti-inflammatory Drug-Stimulated Human Proximal Tubular Cells. Int. J. Mol. Sci. 22(4). doi:10.3390/ijms22041577

Cunningham, K. G., Manson, W., Spring, F. S., and Hutchinson, S. A. (1951). Cordycepin, a Metabolic Product Isolated from Cultures of Cordyceps Militaris (Linn.) Link. Nature 166 (4231), 949. doi: $10.1038 / 166949 \mathrm{a} 0$

Dong, Y., and Gao, D. (1996). "A Novel Process for Synthesis of $\beta$-Hydroxyethl Acrylate," in One Step. Shenyang Chemical Industry (3), 20-21. doi:10.13840/ j.cnki.cn21-1457/tq.1996.03.008 
Dong, Y., Hu, S., Liu, C., Meng, Q., Song, J., Lu, J., et al. (2015). Purification of Polysaccharides from Cordyceps Militaris and Their Anti-hypoxic Effect. Mol. Med. Rep. 11 (2), 1312-1317. doi:10.3892/mmr.2014.2786

Duan, R., Li, H., Li, H., Tang, L., Zhou, H., Yang, X., et al. (2018). Enhancing the Production of D-Mannitol by an Artificial Mutant of Penicillium Sp. T2-M10. Appl. Biochem. Biotechnol. 186 (4), 990-998. doi:10.1007/s12010-018-2791-6

Fan, S., Huang, X., Wang, S., Li, C., Zhang, Z., Xie, M., et al. (2018). Combinatorial Usage of Fungal Polysaccharides from Cordyceps Sinensis and Ganoderma Atrum Ameliorate Drug-Induced Liver Injury in Mice. Food Chem. Toxicol. 119, 66-72. doi:10.1016/j.fct.2018.05.027

Feige, K., Rubbert, J., Raupach, A., Stroethoff, M., Heinen, A., Hollmann, M. W., et al. (2021). Cardioprotective Properties of Mannitol-Involvement of Mitochondrial Potassium Channels. Int. J. Mol. Sci. 22(5). doi:10.3390/ijms22052395

Gong, C., Xu, C., Yang, K., Chen, G., Pan, Z., and Wu, W. (2003). Studies on Toxicities of Silkworm Cordyceps Militaris. Edible Fungi of China 22 (006), 54-56. doi:10.13629/ j.cnki.53-1054.2003.06.025

Gong, C., Xu, C., Yang, K., Chen, G., Pan, Z., and Wu, W. (2004). Studies on Toxicities of Silkworm Cordyceps Militaris. Edible Fungi of China 023 (001), 46-48. doi:10.13629/ j.cnki.53-1054.2004.01.025

Graeff, R., Guedes, A., Quintana, R., Wendt-Hornickle, E., Baldo, C., Walseth, T., et al. (2020). Novel Pathway of Adenosine Generation in the Lungs from NAD(+): Relevance to Allergic Airway Disease. Molecules 25(21), 4966 doi:10.3390/molecules25214966

Guo, M., Guo, S., Huaijun, Y., Bu, N., and Dong, C.-H. (2016). Comparison of Major Bioactive Compounds of the Caterpillar Medicinal Mushroom, Cordyceps Militaris (Ascomycetes), Fruiting Bodies Cultured on Wheat Substrate and Pupae. Int. J. Med. Mushrooms 18 (4), 327-336. doi:10.1615/ IntJMedMushrooms.v18.i4.60

Guo, M., Zhao, Q., Fan, S., Wu, Z., Lin, L., Chen, H., et al. (2021). Characteristics of Arsenic Species in Cerebrospinal Fluid (CSF) of Acute Promyelocytic Leukaemia (APL) Patients Treated with Arsenic Trioxide Plus Mannitol. Br. Jnl Clin. Pharma 87 (10), 4020-4026. doi:10.1111/bcp.14804

Heuser, F., Marin, K., Kaup, B., Bringer, S., and Sahm, H. (2009). Improving D-Mannitol Productivity of Escherichia coli: Impact of NAD, CO2 and Expression of a Putative Sugar Permease from Leuconostoc Pseudomesenteroides. Metab. Eng. 11 (3), 178-183. doi:10.1016/ j.ymben.2009.01.006

Hong, T., Zhang, M., and Fan, J. (2015). Cordyceps Sinensis (A Traditional Chinese Medicine) for Kidney Transplant Recipients. Cochrane Database Syst. Rev. 10, CD009698. doi:10.1002/14651858.CD009698.pub2

Huang, S., Liu, H., Sun, Y., Chen, J., Li, X., Xu, J., et al. (2017). An Effective and Convenient Synthesis of Cordycepin from Adenosine. Chem. Pap. 72 (1), 149-160. doi:10.1007/s11696-017-0266-9

Huo, C., Li, H., Li, Q., Wang, J., Li, C., and Wang, L. (2021). Construction and Optimization of Cordycepin-Producing Saccharomyces cerevisiae. Sheng $W u$ Gong Cheng Xue Bao 37 (9), 3334-3347. doi:10.13345/j.cjb.200738

Jang, H. J., Yang, K. E., wang, I. H., Huh, Y. H., Kim, D. J., Yoo, H. S., et al. (2019). Cordycepin Inhibits Human Ovarian Cancer by Inducing Autophagy and Apoptosis Through Dickkopf-Related Protein 1/ $\beta$-Catenin Signaling. Am. J. Transl. Res. 11 (11), 6890-6906. doi:10.1016/j.jams.2020.03.007

Jin, S., and Li, Y. (2006). The Production Method of D-Mannitol. StarchStarke 37 (4), 136-141. doi:10.1002/star.19850370409

Jin, Y., Meng, X., Qiu, Z., Su, Y., Yu, P., and Qu, P. (2018). Anti-tumor and Antimetastatic Roles of Cordycepin, One Bioactive Compound of Cordyceps Militaris. Saudi J. Biol. Sci. 25 (5), 991-995. doi:10.1016/j.sjbs.2018.05.016

Kang, N., Lee, H.-H., Park, I., and Seo, Y.-S. (2017). Development of High Cordycepin-Producing Cordyceps Militaris Strains. Mycobiology 45 (1), 31-38. doi:10.5941/myco.2017.45.1.31

Kato, T., Ahmad, S., and Park, E. Y. (2017). Functional Analysis of Ribonucleotide Reductase from Cordyceps Militaris Expressed in Escherichia coli. Appl. Biochem. Biotechnol. 182 (4), 1307-1317. doi:10.1007/s12010-017-2400-0

Kaup, B., Bringer-Meyer, S., and Sahm, H. (2005). D-Mannitol Formation from D-Glucose in a Whole-Cell Biotransformation with Recombinant Escherichia coli. Appl. Microbiol. Biotechnol. 69 (4), 397-403. doi:10.1007/s00253-005-1996-0

Kaup, B., Bringer-Meyer, S., and Sahm, H. (2004). Metabolic Engineering of Escherichia coli: Construction of an Efficient Biocatalyst for D-Mannitol Formation in a Whole-Cell Biotransformation. Appl. Microbiol. Biotechnol. 64 (3), 333-339. doi:10.1007/s00253-003-1470-9
Kim, H. W., Kim, Y. H., Cai, X. F., Nam, K. S., and Hyun, J. W. (2001). In Vitro Antitumor Activity of Ergosterol Peroxide Isolated from Cordyceps Militaris on Cancer Cell Lines from Korean Patients. Korean J. Mycol., 29, 1, 61-66.

Kim, S. W., Xu, C. P., Hwang, H. J., Choi, J. W., Kim, C. W., and Yun, J. W. (2003). Production and Characterization of Exopolysaccharides from an Enthomopathogenic Fungus Cordyceps Militaris NG3. Biotechnol. Prog. 19 (2), 428-435. doi:10.1021/bp025644k

Lee, J. S., Kwon, J. S., Won, D. P., Lee, J. H., Lee, K. E., Lee, S. Y., et al. (2010). Study of Macrophage Activation and Structural Characteristics of Purified Polysaccharide from the Fruiting Body of Cordyceps Militaris. J. Microbiol. Biotechnol. 20 (7), 1053-1060. doi:10.4014/jmb.0910.10022

Lei, L., Zhao, F., Han, S., and Zhang, Y. (2020). Enhanced Rhamnolipids Production in Pseudomonas aeruginosa SG by Selectively Blocking Metabolic Bypasses of Glycosyl and Fatty Acid Precursors. Biotechnol. Lett. 42 (6), 997-1002. doi:10.1007/s10529-020-02838-9

Li, I.-C., Lin, S., Tsai, Y.-T., Hsu, J.-H., Chen, Y.-L., Lin, W.-H., et al. (2019a). Cordyceps Cicadae Mycelia and its Active Compound HEA Exert Beneficial Effects on Blood Glucose in Type 2 Diabetic Db/db Mice. J. Sci. Food Agric. 99 (2), 606-612. doi:10.1002/jsfa.9221

Li, J., Zhong, L., Zhu, H., and Wang, F. (2017). The Protective Effect of Cordycepin on D-Galactosamine/Lipopolysaccharide-Induced Acute Liver Injury. Mediators Inflamm. 2017, 3946706. doi:10.1155/2017/3946706

Li, X., Liu, Q., Li, W., Li, Q., Qian, Z., Liu, X., et al. (2019b). A Breakthrough in the Artificial Cultivation of Chinese Cordyceps on a Large-Scale and its Impact on Science, the Economy, and Industry. Crit. Rev. Biotechnol. 39 (2), 181-191. doi:10.1080/07388551.2018.1531820

Lin, S., Liu, Z.-Q., Baker, P. J., Yi, M., Wu, H., Xu, F., et al. (2016a). Enhancement of Cordyceps Polysaccharide Production via Biosynthetic Pathway Analysis in Hirsutella Sinensis. Int. J. Biol. Macromolecules 92, 872-880. doi:10.1016/j.ijbiomac.2016.08.002

Lin, S., Liu, Z.-Q., Xue, Y.-P., Baker, P. J., Wu, H., Xu, F., et al. (2016b). Biosynthetic Pathway Analysis for Improving the Cordycepin and Cordycepic Acid Production in Hirsutella Sinensis. Appl. Biochem. Biotechnol. 179 (4), 633-649. doi:10.1007/s12010-016-2020-0

Liu, W., Zhang, L., Sun, S., Tang, L.-s., He, S.-m., Chen, A.-q., et al. (2021). Cordycepin Inhibits Inflammatory Responses through Suppression of ERK Activation in Zebrafish. Developmental Comp. Immunol. 124, 104178. doi:10.1016/j.dci.2021.104178

Liu, X., Zhong, F., Tang, X.-l., Lian, F.-l., Zhou, Q., Guo, S.-m., et al. (2014). Cordyceps Sinensis Protects against Liver and Heart Injuries in a Rat Model of Chronic Kidney Disease: a Metabolomic Analysis. Acta Pharmacol. Sin. 35 (5), 697-706. doi:10.1038/aps.2013.186

Long, H., Qiu, X., Cao, L., Liu, G., Rao, Z., and Han, R. (2021). Toxicological Safety Evaluation of the Cultivated Chinese Cordyceps. J. Ethnopharmacology 268, 113600. doi:10.1016/j.jep.2020.113600

Lou, H. W., Zhao, Y., Chen, B. X., Yu, Y. H., Tang, H. B., Ye, Z. W., et al. (2020). Cmfhp Gene Mediates Fruiting Body Development and Carotenoid Production in Cordyceps Militaris. Biomolecules 10(3). doi:10.3390/biom10030410

Luo, X., Duan, Y., Yang, W., Zhang, H., Li, C., and Zhang, J. (2017). Structural Elucidation and Immunostimulatory Activity of Polysaccharide Isolated by Subcritical Water Extraction from Cordyceps Militaris. Carbohydr. Polym. 157, 794-802. doi:10.1016/j.carbpol.2016.10.066

Madsen, M. A., Semerdzhiev, S., Amtmann, A., and Tonon, T. (2018). Engineering Mannitol Biosynthesis in Escherichia coli and Synechococcus Sp. PCC 7002 Using a Green Algal Fusion Protein. ACS Synth. Biol. 7 (12), 2833-2840. doi:10.1021/acssynbio.8b00238

Nakamura, K., Shinozuka, K., and Yoshikawa, N. (2015). Anticancer and Antimetastatic Effects of Cordycepin, an Active Component of Cordyceps Sinensis. J. Pharmacol. Sci. 127 (1), 53-56. doi:10.1016/j.jphs.2014.09.001

Ohta, Y., Lee, J.-B., Hayashi, K., Fujita, A., Park, D. K., and Hayashi, T. (2007). In Vivo Anti-influenza Virus Activity of an Immunomodulatory Acidic Polysaccharide Isolated from Cordyceps Militaris Grown on Germinated Soybeans. J. Agric. Food Chem. 55 (25), 10194-10199. doi:10.1021/jf0721287

Park, J. J., and Lee, W. Y. (2021). Anti-glycation Effect of Ecklonia Cava Polysaccharides Extracted by Combined Ultrasound and Enzyme-Assisted Extraction. Int. J. Biol. Macromolecules 180, 684-691. doi:10.1016/j.ijbiomac.2021.03.118

Qu, J., Zhong, Y., Ding, L., Liu, X., Xu, S., Guo, D., et al. (2022). Biosynthesis, Structure and Functionality of Starch Granules in maize Inbred Lines with Different Kernel Dehydration Rate. Food Chem. 368. doi:10.1016/ j.foodchem.2021.130796 
Rathor, P., Borza, T., Liu, Y., Qin, Y., Stone, S., Zhang, J., et al. (2020). Low Mannitol Concentrations in Arabidopsis thaliana Expressing Ectocarpus Genes Improve Salt Tolerance. Plants 9(11). doi:10.3390/plants9111508

Reshamwala, S. M. S., Pagar, S. K., Velhal, V. S., Maranholakar, V. M., Talangkar, V. G., and Lali, A. M. (2014). Construction of an Efficient Escherichia coli Whole-Cell Biocatalyst for D-Mannitol Production. J. Biosci. Bioeng. 118 (6), 628-631. doi:10.1016/j.jbiosc.2014.05.004

Rice, T., Sahin, A. W., Lynch, K. M., Arendt, E. K., and Coffey, A. (2020). Isolation, Characterisation and Exploitation of Lactic Acid Bacteria Capable of Efficient Conversion of Sugars to Mannitol. Int. J. Food Microbiol. 321, 108546. doi:10.1016/j.ijfoodmicro.2020.108546

Sari, N., Suparmin, A., Kato, T., and Park, E. Y. (2016). Improved Cordycepin Production in a Liquid Surface Culture of Cordyceps Militaris Isolated from Wild Strain. Biotechnol. Bioproc. E 21 (5), 595-600. doi:10.1007/s12257-016-0405-0

Smiderle, F. R., Baggio, C. H., Borato, D. G., Santana-Filho, A. P., Sassaki, G. L., Iacomini, M., et al. (2014). Anti-Inflammatory Properties of the Medicinal Mushroom Cordyceps Militaris Might Be Related to its Linear $(1 \rightarrow 3)-\beta-D-$ Glucan. PLoS One 9 (10), e110266. doi:10.1371/journal.pone.0110266

Tang, J., Qian, Z., and Wu, H. (2018). Enhancing Cordycepin Production in Liquid Static Cultivation of Cordyceps Militaris by Adding Vegetable Oils as the Secondary Carbon Source. Bioresour. Technology 268, 60-67. doi:10.1016/ j.biortech.2018.07.128

Teh, M. Y., Ooi, K. H., Danny Teo, S. X., Bin Mansoor, M. E., Shaun Lim, W. Z., and Tan, M. H. (2019). An Expanded Synthetic Biology Toolkit for Gene Expression Control in Acetobacteraceae. ACS Synth. Biol. 8 (4), 708-723. doi:10.1021/acssynbio.8b00168

Ukai, S., Kiho, T., Hara, C., Morita, M., Goto, A., Imaizumi, N., et al. (1983). Polysaccharides in Fungi. XIII. Antitumor Activity of Various Polysaccharides Isolated from Dictyophora Indusiata, Ganoderma Japonicum, Cordyceps Cicadae, Auricularia Auricula-Judae, and Auricularia Species. Chem. Pharm. Bull. 31 (2), 741-744. doi:10.1248/cpb.31.741

Wang, H. B., Duan, M. X., Xu, M., Huang, S. H., Yang, J., Yang, J., et al. (2019a). Cordycepin Ameliorates Cardiac Hypertrophy via Activating the AMPKa Pathway. J. Cel. Mol. Med. 23 (8), 5715-5727. doi:10.1111/jcmm.14485

Wang, J., Wang, Y., Yang, X., Lin, P., Liu, N., Li, X., et al. (2021). Purification, Structural Characterization, and PCSK9 Secretion Inhibitory Effect of the Novel Alkali-Extracted Polysaccharide from Cordyceps Militaris. Int. J. Biol. Macromolecules 179, 407-417. doi:10.1016/j.ijbiomac.2021.02.191

Wang, N., Li, J., Huang, X., Chen, W., and Chen, Y. (2016). Herbal Medicine Cordyceps Sinensis Improves Health-Related Quality of Life in Moderate-ToSevere Asthma. Evid. Based Complement. Alternat. Med. 2016, 6134593. doi:10.1155/2016/6134593

Wang, X., Qin, A., Xiao, F., Olatunji, O. J., Zhang, S., Pan, D., et al. (2019b). N6 -(2Hydroxyethyl)-Adenosine from Cordyceps Cicadae Protects against Diabetic Kidney Disease via Alleviation of Oxidative Stress and Inflammation. J. Food Biochem. 43 (2), e12727. doi:10.1111/jfbc.12727

Wang, Y., Zhang, G., Zhao, X., and Ling, J. (2017). Genome Shuffling Improved the Nucleosides Production in Cordyceps Kyushuensis. J. Biotechnol. 260, 42-47. doi:10.1016/j.jbiotec.2017.08.021

Wei, X., Li, Q., Hu, C., and You, C. (2021). An ATP-free In Vitro Synthetic Enzymatic Biosystem Facilitating One-Pot Stoichiometric Conversion of Starch to Mannitol. Appl. Microbiol. Biotechnol. 105 (5), 1913-1924. doi:10.1007/s00253-021-11154-9

Wongsa, B., Raethong, N., Chumnanpuen, P., Wong-Ekkabut, J., Laoteng, K., and Vongsangnak, W. (2020). Alternative Metabolic Routes in Channeling Xylose to Cordycepin Production of Cordyceps Militaris Identified by Comparative Transcriptome Analysis. Genomics 112 (1), 629-636. doi:10.1016/j.ygeno.2019.04.015

Xia, Y., Luo, F., Shang, Y., Chen, P., Lu, Y., and Wang, C. (2017). Fungal Cordycepin Biosynthesis Is Coupled with the Production of the Safeguard Molecule Pentostatin. Cel Chem. Biol. 24 (12), 1479-1489. doi:10.1016/j.chembiol.2017.09.001

Xiang, L., Li, Y., Zhu, Y., Luo, H., Li, C., Xu, X., et al. (2014). Transcriptome Analysis of the Ophiocordyceps Sinensis Fruiting Body Reveals Putative Genes Involved in Fruiting Body Development and Cordycepin Biosynthesis. Genomics 103 (1), 154-159. doi:10.1016/j.ygeno.2014.01.002

Xiao, H., Bang-Berthelsen, C. H., Jensen, P. R., Solem, C., and Ercolini, D. (2021). Deciphering the Regulation of the Mannitol Operon Paves the Way for Efficient Production of Mannitol in Lactococcus Lactis. Appl. Environ. Microbiol. 87 (16). doi:10.1128/aem.00779-21

Xie, H., Li, X., Yang, W., Yu, L., Jiang, X., Chen, Y., et al. (2020). N6-(2hydroxyethyl)-Adenosine Induces Apoptosis via ER Stress and Autophagy of Gastric Carcinoma Cells In Vitro and. Vivo. Int. J. Mol. Sci. 21 (16). doi:10.3390/ijms21165815

Yu, R., Wang, L., Zhang, H., Zhou, C., and Zhao, Y. (2004b). Isolation, Purification and Identification of Polysaccharides from Cultured Cordyceps Militaris. Fitoterapia 75 (7-8), 662-666. doi:10.1016/j.fitote.2004.06.010

Yu, R., Song, L., Zhao, Y., Bin, W., Wang, L., Zhang, H., et al. (2004a). Isolation and Biological Properties of Polysaccharide CPS-1 from Cultured Cordyceps Militaris. Fitoterapia 75 (5), 465-472. doi:10.1016/j.fitote.2004.04.003

Zeng, Y., Han, Z., Qiu, P., Zhou, Z., Tang, Y., Zhao, Y., et al. (2014). Salinityinduced Anti-angiogenesis Activities and Structural Changes of the Polysaccharides from Cultured Cordyceps Militaris. PLoS One 9 (9), e103880. doi:10.1371/journal.pone.0103880

Zhang, H., Deng, L., Zhang, Z., Guan, Y., Li, B., Yang, J., et al. (2020a). Enhanced Cordycepin Production in Caterpillar Medicinal Mushroom, Cordyceps Militaris (Ascomycetes), Mutated by a Multifunctional Plasma Mutagenesis System. Int. J. Med. Mushrooms 22 (12), 1147-1159. doi:10.1615/ intjmedmushrooms.2020037153

Zhang, H., Wang, Y.-X., Tong, X.-X., Yokoyama, W., Cao, J., Wang, F., et al. (2020b). Overexpression of Ribonucleotide Reductase Small Subunit, RNRM, Increases Cordycepin Biosynthesis in Transformed Cordyceps Militaris. Chin. J. Nat. Medicines 18 (5), 393-400. doi:10.1016/s1875-5364(20)30046-7

Zhang, H. W., Lin, Z. X., Tung, Y. S., Kwan, T. H., Mok, C. K., Leung, C., et al. (2014). Cordyceps Sinensis (A Traditional Chinese Medicine) for Treating Chronic Kidney Disease. Cochrane Database Syst Rev 18 (12), CD008353. doi:10.1002/14651858.CD008353.pub2

Zhang, J., Wen, C., Duan, Y., Zhang, H., and Ma, H. (2019). Advance in Cordyceps Militaris (Linn) Link Polysaccharides: Isolation, Structure, and Bioactivities: A Review. Int. J. Biol. Macromolecules 132, 906-914. doi:10.1016/ j.ijbiomac.2019.04.020

Zhang, Y., Zeng, Y., Cui, Y., Liu, H., Dong, C., and Sun, Y. (2020c). Structural Characterization, Antioxidant and Immunomodulatory Activities of a Neutral Polysaccharide from Cordyceps Militaris Cultivated on hull-less Barley. Carbohydr. Polym. 235, 115969. doi:10.1016/j.carbpol.2020.115969

Zhang, Z., Tudi, T., Liu, Y., Zhou, S., Feng, N., Yang, Y., et al. (2016). Preparative Isolation of Cordycepin, N 6 -(2-Hydroxyethyl)-Adenosine and Adenosine from Cordyceps Militaris by Macroporous Resin and Purification by Recycling High-Speed Counter-current Chromatography. J. Chromatogr. B 1033-1034, 218-225. doi:10.1016/j.jchromb.2016.08.025

Zhao, X., Zhang, G., Li, C., and Ling, J. (2019). Cordycepin and Pentostatin Biosynthesis Gene Identified through Transcriptome and Proteomics Analysis of Cordyceps Kyushuensis Kob. Microbiol. Res. 218, 12-21. doi:10.1016/ j.micres.2018.09.005

Zheng, P., Xia, Y., Xiao, G., Xiong, C., Hu, X., Zhang, S., et al. (2011). Genome Sequence of the Insect Pathogenic Fungus Cordyceps Militaris, a Valued Traditional Chinese Medicine. Genome Biol. 12 (11), R116. doi:10.1186/gb-2011-12-11-r116

Zhou, J., Bai, Y., Dai, R., Guo, X., Liu, Z.-H., and Yuan, S. (2018). Improved Polysaccharide Production by Homologous Co-overexpression of Phosphoglucomutase and UDP Glucose Pyrophosphorylase Genes in the Mushroom Coprinopsis Cinerea. J. Agric. Food Chem. 66 (18), 4702-4709. doi:10.1021/acs.jafc.8b01343

Conflict of Interest: The authors declare that the research was conducted in the absence of any commercial or financial relationships that could be construed as a potential conflict of interest.

Publisher's Note: All claims expressed in this article are solely those of the authors and do not necessarily represent those of their affiliated organizations, or those of the publisher, the editors and the reviewers. Any product that may be evaluated in this article, or claim that may be made by its manufacturer, is not guaranteed or endorsed by the publisher.

Copyright (c) $2021 \mathrm{Wu}, \mathrm{Wu}$, Huang, Shen, Zhang, Song, Wang and Ruan. This is an open-access article distributed under the terms of the Creative Commons Attribution License (CC BY). The use, distribution or reproduction in other forums is permitted, provided the original author(s) and the copyright owner(s) are credited and that the original publication in this journal is cited, in accordance with accepted academic practice. No use, distribution or reproduction is permitted which does not comply with these terms. 